\section{International Scientific Journal Theoretical \& Applied Science}

Inna Aleksandrovna Serebryanik

Candidate of technical sciences, associate professor, Associate Professor of the Department of World economy Irkutsk National Research Technical University nasamolet@yandex.ru

Natalia Mihaylovna Olah master

Irkutsk National Research Technical University

SECTION 4. Computer science, computer engineering and automation.

\title{
INFOGRAPHIC: SOLVING BUSINESS PROBLEMS
}

Abstract: Analyzed the concept of infographics. Shows the main species. Analyzed technology for creating infographics.

Key words: infographic, business infographic, design, big data, chart.

Language: Russian

Citation: Serebryanik IA, Olah NM (2016) INFOGRAPHIC: SOLVING BUSINESS PROBLEMS. ISJ Theoretical \& Applied Science, 04 (36): 40-42.

Soi: http://s-o-i.org/1.1/TAS-04-36-7 Doi: crossef http://dx.doi.org/10.15863/TAS.2016.04.36.7

\section{ИНФОГРАФИКА: РЕШЕНИЕ БИЗНЕС-ЗАДАЧ}

\author{
Аннотация: Проанализировано понятие инфографики. Показаны основнье ее виды. \\ Проанализирована технология создания инфографики. \\ Ключевые слова: инфографика, бизнес-инфографика, дизайн, большие данные, диаграмма.
}

Термин «инфографика» раскладывается на два слова - информация и графика, следовательно, инфографика - это способ передачи информации с помощью графики и текста.

Более точное определение инфографики можно дать такое. Это визуализация информации в целях последующего анализа, выявление взаимосвязей и представления корреляции между несколькими массивами данных в удобной форме, позволяющей наблюдателю быстро разобраться в представленной информации.

Самая простая инфографика - это графики, диаграммы, карты и т.д.

Инфографика не новое изобретение, но является современным и модным средством.

Самая первая инфографика - это наскальные рисунки. Средневековые навигационные карты, таблицы расположений звёзд, анатомические рисунки с подписями - всё это ранние примеры инфографики. Интересно, что еще в 1854 году Джону Сноу удалось остановить эпидемию холеры в Лондоне с помощью инфографики. Он нарисовал схему города и точками обозначил очаги заболевания. Так практически все крестики на карте показали на местность возле одной из водонапорных башен. Закрыв ее, удалось предотвратить появление новых случаев заболевания.

Газета USA Today с 1982 года активно использует сочетание графики и текста, благодаря чему вошла в пятерку самых просматриваемых изданий США. Для новостного издания инфографика просто находка. Один рисунок может заменить несколько страниц текста.

Среди лучших примеров инфографики в мировых средствах массовой информации - это американская The New York Times, испанские EL Mundo и El País. Среди журналов лидером является National Geographic.

Инфографика используется в различных областях. В печатных изданиях, рекламе и маркетинге, образовании, науке и т.д. Интересна инфографика и для бизнеса. С помощью нее может быть представлен отчет компании, план развития и так далее.

Причины популярности инфографики:

1. Инфографика прекрасно усваивается, так как примерно 80/90\% информации человек получает, используя зрение, а только 20/10\% - другие органы чувств;

2. Массивы информации с каждым годом растут, а обрабатывать их становится сложнее; 
3. Статистические данные помогают нам хорошо понимать окружающий мир.

В основе инфографики лежит, прежде всего, ИНФОРМИРОВАНИЕ, а потом уже ДИЗАЙН. Инфографика может перевести массивы данных в полезную и понятную для пользователя информацию.

Принципы хорошей инфографики:

1. если убрать текст, то смысл изображения все равно понятен;

2. если убрать цифры, то смысл все равно понятен.

Часто инфографики ассоциируют с клиповым представлением информации, однако, это не так. В инфографике нужно уметь разбираться.

Существует несколько видов инфографики:

1. Статичная инфографика - отражает факты и цифры. Это простейшие диаграммы, графики и др.

2. Инфографика, отображающая процесс, цепочку действий, последовательность. Это инструкции, хронологические карты, рецепты, изображенные в виде графических или символьных схем.

3. Инфографика-инструкция. Объяснение устройства, принципа работы.

4. Динамичная инфографика показывает динамику развития или процесс.

5. Видео-инфографика. Чаще всего используется для видео описания товар или услуги компании.

6. Бизнес-инфографика. Часто используется как история успеха компании в картинках.

7. Инфографика как реклама.

По уровню сложности инфографика делится на:

1. Простейшая визуализация - это визуализация больших объемов цифровых данных;

2. Полноценной инфографика - «история» за пределами цифр.

3. Сложная инфографика. Отсутствие данных, только определенный набор идей и понятий, имеющих/не имеющих логические взаимосвязи, которые необходимо отобразить.

По типу источника различают 3 основных вида инфографики:

1. Аналитическая инфографика;

2. Инфографика реконструкции;

3. Новостная инфографика.

По плотности представленной информации инфографика делится на:

1. Ненасыщенная, т.е. простая, построенная вокруг нескольких цифр
2. Концентрированная, т.е плотная, сложная, построенная как совокупность изображения и целого ряда цифр.

В бизнесе многие моменты могут быть успешно визуализированы с помощью инфографики, например:

1. Отчеты любого уровня;

2. Бюджеты;

3. Новости, которые готовятся для клиентов;

4. Технические задания;

5. Сложная информация для наполнения сайта (например, миссия и цели компании);

6. И др.

Основное отличие бизнес-инфографики от инфографики в другой сфере - это точность.

Этапы создания инфографики:

1. Выбор темы. Руководствуемся

актуальностью и востребованностью;

2. Сбор информации;

3. Сортировка информации. Оставляем самую важную информацию по теме;

4. Выбор типа инфографики. Это может быть схема, карта, график, диаграмма, рисунок или что-то другое;

5. Создание эскиза;

6. Планирование и работа над графикой;

7. Сборка графики на основе эскиза.

Для того, чтобы сделать инфографику необходимы знания и умения журналиста, а также дизайнера. На практике это, как правило, выделенный специалист, у которого одинаково хорошо работают и правое, и левое полушарие.

Многие хорошие специалисты по инфографике пришли не из дизайна, а из других специальностей.

Инфографику легко испортить, например, излишне насытив ее графикой. Важное знание необходимо уделять центральному элементу инфографики.

Нельзя пытаться визуализировать 100\% информации, усвоить ее будет невозможно.

Некоторые паразитируют на инфографике, не придумывая ничего нового, паразитируют на уже созданном ранее контенте. Надо всегда помнить, что если контент не интересен, то никакая инфографика его не спасет.

Сегодня рынок инфографики существенно перегрет, потому она часто теряет в качестве, становится фаст-фудом. Даже появилось понятие «в стиле инфографики».

Инфографике практически не учат в России. В 2005 году в МГУ (Журфак) пытались открыть специальность «Инфографика», но ничего хорошего из этой затеи не вышло. Курса «Инфографика» нет ни в одном учебном плане. В США Инфографика - серьезная специальность, 


\begin{tabular}{|c|c|c|c|c|c|c|}
\hline Impact Factor: & $\begin{array}{l}\text { ISRA (India) } \\
\text { ISI (Dubai, UAE } \\
\text { GIF (Australia) } \\
\text { JIF }\end{array}$ & $\begin{array}{l}=1.344 \\
=0.829 \\
=0.564 \\
=1.500\end{array}$ & $\begin{array}{l}\text { SIS (USA) } \\
\text { PИНЦ (Russia) } \\
\text { ESJI (KZ) } \\
\text { SJIF (Morocco) }\end{array}$ & $\begin{array}{l}=0.912 \\
=0.234 \\
=1.042 \\
=2.031\end{array}$ & $\begin{array}{l}\text { ICV (Poland) } \\
\text { PIF (India) } \\
\text { IBI (India) }\end{array}$ & $\begin{array}{l}=6.630 \\
=1.940 \\
=4.260\end{array}$ \\
\hline
\end{tabular}

которую преподают, как теоретики, так и практики.

В России с 2011 года выпускается журнал «Инфографика», все его статьи написаны именно в графической форме. Он распространяется бесплатно. Больше нет аналогов. В Европе инфографика более популярна, чем, в России. Например, в Германии есть платные издания.

Ресурсы для создания инфографики:

1. Infogr.am Хорош для новичков. По стилистике напоминает Instagram. Необходима регистрации или возможен вход через профили социальных сетей. Содержит 6 готовых шаблонов. Редактирование данных происходит в таблице, которая внешне похожа на Excel.

2. Piktochart Очень прост в использовании. Базовые функции сервиса бесплатные, но расширенные необходимо будет купить.

3. Easel.ly. Сервис без регистрации. Содержит готовые шаблоны. Работает сервис по принципу drag \& drop (перетащи и брось). Каждому элементу можно придавать нужную величину и форму. Сохранять готовый проект можно в форматах Jpeg и PDF.

4. И др.

Тренды в инфографике. Bо-первых, инфографика становится все более точной и отточенной, что касается дизайна. Во-вторых, возрастает роль аналитической составляющей. B-третьих, обозначилась сверхзадача - создание аналитической инструментов для работь с большими данными (big data).

Цены на инфографику. Сегодня в России многие компанию делают инфографику на заказ. Расценки различны. Например, изготовление ролика с элементами инфографики обойдется от 100 до 200 тыс. рублей. Средняя стоимость одного листа инфографики составляет 300-700\$.

\section{References:}

1. (2016) - Infografika. Arhiv zhurnala. Available: http://infographicsmag.ru/journal (Accessed: 10.04.2016).

2. (2016) - In-fografika i dizajn Available: http://infogra.ru/ (Accessed: 10.04.2016).

3. (2016) - Test infografika Available: http://infographer.ru/ (Accessed: 10.04.2016).

4. (2016) - Infografika so vsego sveta. Available: http://infografics.ru/ (Accessed: 10.04.2016).

5. (2012) Informotion: Animated Infographics. Gestalten Verlag. 2012. - 208 p.

6. Chernjak L (2013) Infografi-ka: ot istokov k sovremennosti.

http://www.osp.ru/os/2013/05/13036001/

(Accessed: 10.04.2016).
7. Klifford D (2014) Ikony graficheskogo dizajna. Moscow: JeKSMO, 2014. pp.240

8. Larot $\mathrm{T}$ (2013) Infografi-ka: vmesto tysjachi slov. //Zhurnalist - №5 - 2013. pp.37-39

9. Makkjendless D (2013) Info-grafika. Samye inte-resnye dannye $\mathrm{v}$ gra-ficheskom predstavlenii. 2013. - 264 p.

10. Nekrasova SV (2015) IN-FOGRAFIKA: novye vozmozhnosti ili pus-taja trata vremeni? http://sb.litera-ml.ru/assets/files/Fulltext/92015/Nekrasova_9_15.pdf (Accessed: 10.04.2016). 